\title{
On the Independent Origins of Complex Brains and Neurons
}

\author{
Leonid L. Moroz \\ Department of Neuroscience and McKnight Brain Institute, Gainesville, Fla., and Whitney Laboratory for \\ Marine Bioscience, University of Florida, St. Augustine, Fla., USA
}

\section{Key Words}

Evolution of nervous systems · Evolution of neurons • Mollusca $\cdot$ Hemichodata $\cdot$ Basal Metazoa $\cdot$ Cell lineages $\cdot$ Neurotransmitters $\cdot$ Genomes $\cdot$ Ctenophora

\begin{abstract}
Analysis of the origin and evolution of neurons is crucial for revealing principles of organization of neural circuits with unexpected implications for genomic sciences, biomedical applications and regenerative medicine. This article presents an overview of some controversial ideas about the origin and evolution of neurons and nervous systems, focusing on the independent origin of complex brains and possible independent origins of neurons. First, earlier hypotheses related to the origin of neurons are summarized. Second, the diversity of nervous systems and convergent evolution of complex brains in relation to current views about animal phylogeny is discussed. Third, the lineages of molluscs and basal metazoans are used as illustrated examples of multiple origins of complex brains and neurons. Finally, a hypothesis about the independent origin of complex brains, centralized nervous systems and neurons is outlined. Injury-associated mechanisms leading to secretion of signal peptides (and related molecules) can be considered as evolutionary predecessors of inter-neuronal signaling and the major factors in the appearance of neurons in the first place.
\end{abstract}

Copyright $\odot 2009$ S. Karger AG, Basel

\section{KARGER}

Fax +4161306 1234

E-Mail karger@karger.ch

www.karger.com
(C) 2009 S. Karger AG, Basel

Accessible online at: www.karger.com/bbe

\section{Theories on the Origin of Nervous Systems and Neurons}

Arrays of hypotheses related to the evolution of central nervous systems (CNSs) and neurons can be broadly presented as two classical scenarios: monophyly versus polygenesis. Monophyly means the origin of neurons from a single ancestral cell lineage. Similarly, the genealogy of a complex brain can be traced back to the ancestral CNS or to a centralized 'nerve cord' present in a common ancestor of bilaterian animals (Urbilateria) or all animals. Traditionally, the idea of monophyly is derived from the classical Darwinian concept of a 'last common ancestor'. On the level of species and organisms this approach is the foundation of biology and phylogeny. On the level of specific cells, cell populations or tissues, finding a common predecessor or single ancestral cellular lineage for neurons or muscles across phyla is problematic.

In contrast, polygenesis refers to polyphyletic origin (polyphyly), or independent origins of neurons and complex brains among species in different lineages. It is a result of the widespread process of parallel evolution of cell types and neuronal complexity within the majority of animal groups. In my opinion, multiple origins better explains the extant diversity of nervous systems and enormous plasticity in establishment of complex cell phenotypes, development and differentiation programs, transdifferentiation, and redundancy of molecular com- 
ponents in signal transduction pathways. It offers the possibility to achieve similar neuron-like phenotypes as a result of the combination of evolutionarily conserved molecular regulatory modules (which sometimes reach a convergence in certain cell phenotypes) rather than requiring common ancestry from a single particular cell lineage that would be a predecessor of all neurons and nervous systems in more than 30 phyla. Of course, in the extreme case, every cell can be traced to a single oocyte, but specialized cell lineages (e.g. those leading to distinct neuronal classes or sensory cells) can be independently derived/evolved at different stages from different embryonic layers later in development.

\section{Earlier Theories}

Earlier theories on neuronal origin are important to consider in terms of monophyly versus polygenesis of neurons and CNSs [see also Bullock and Horridge, 1965; Lentz, 1968; and Lichtneckert and Reichert, 2007 for historical reviews of the earlier concepts on the origin of neuronal organization].

The first theory on the origin of neurons was presented by Nicolaus Kleinenberg, a German biologist who had obtained a doctorate degree under Ernst Haeckel. In his anatomical-evolutionaryinvestigation of $\mathrm{Hydra}$ [Kleinenberg, 1872], Kleinenberg had discovered polarized cells with two processes: one 'sensory' facing the environment and the second with a possible motor function. Kleinenberg named these cells 'neuromuscular' and suggested they might represent an ancestral stage that gave rise to both pure neuronal and pure muscular cells. In other words, he believed these cells might have all the required components of a reflex-type circuit - the nervous arc the receptor, conductor and effector. Later, these cells were identified as epithelio-muscular cells. In modern terms we might consider this hypothesis as an ultimate monophyly with a common cell lineage ancestor for all neurons, sensory cells and muscles.

Interestingly, the second hypothesis of neuronal origin was also introduced by two other Haeckel students and today can be interpreted in general terms of polygenesis. Brothers Oscar and Richard Hertwig, working on the nervous systems of medusas [Hertwig and Hertwig, 1878], suggested that the receptor, conductor and effector arose as separate types of cells from separate epithelial cells. In this earlier report, the focus was directed to the separate origins of functionally different but physiologically interacting cell types such as specialized sensory cells, conducting neurons or muscle cells. Similar ideas were suggested by Claus [1878] and Chun [1880] working on medusas and ctenophores, respectively. They proposed that following their independent origins, nerve and muscle cells become associated only secondarily.

The most widely acknowledged systematic analysis on the origin of nervous systems was presented by George Howard Parker in his book 'The Elementary Nervous Systems' [Parker, 1919]. Parker distinguished separate stages in the origin of major components of neuronal organization such as the effectors (e.g. muscle and gland cells), sensory organs (or receptors) and the adjustors (or central nervous organs). The first stage can be found in sponges with effectors but not receptors or adjustors. The second stage can be potentially observed in Coelenterates (cnidarians and ctenophores) that can form receptor-effector systems. The next stage is the development of an intermediate (adjuster/or central organ) between receptor and effector; typically characteristic of more complex systems in invertebrates and vertebrates. In these earlier works adjusters can be related to what we now call neurons.

In other words, this hypothesis could be interpreted today as describing stages in the origin of sensory neurons/receptors, motoneurons/effectors and interneurons within the nervous system itself (although Parker did not discuss this scenario). Effectors in Parker's hypothesis were considered as non-neuronal cells, including those already existing in sponges. Receptors arose by the modification of epithelial cells in close proximity to already differentiated muscle cells and were able to make direct connections to muscle cells. This stage has not been clearly defined in extant animals, although the final stages with neuronal elements (adjusters) are widely represented across all animals with nervous systems. According to Parker, the nervous systems in coelenterates form diffuse nerve nets that are not centralized; signal transmission is diffusely spread through the animal's body. Polarized transmission via mediated synapses was considered the essential step toward the origin of a true central nervous system organ [see also Lentz,1968].

\section{Later 20th Century Theories: Integration and Electrical Coupling as Driving Forces of Neuronal} Evolution

Modifications to Parker's hypotheses were done by Pantin and Passano in the 1950s-1960s by introducing integrative and pacemaker components into earlier neural circuits (these might also arise in parallel/independently in evolution) and recognizing that coelenterate nervous systems are also polarized with defined synapses (although some of these synapses can be symmetrical), 
and consist of several relatively independent nerve nets allowing well-coordinated and sometimes complex behaviors [Mackie, 1990].

Coordination and electrical coupling was at the core of these theories. Pantin proposed that a nervous system originated as complex circuits innervating various motor units to produce a coordinated behavior in an animal [Pantin, 1956]. Passano had suggested that neurons arose from pacemaker-type cells that might derive from promyocytes and function to generate contractions in promyocytes and later in true muscle cells [Passano, 1963].

Mackie has further developed this idea suggesting that a nervous system might be derived from electrically coupled primordial myoepithelial-like cells that were capable of reception, transmission and contractions [Mackie, 1970]. Promyocytes were eventually segregated from these primordial cells and protoneurons were evolved from the same epithelial cells (which lost their contractile component) to convey excitation to myocytes, and possibly other cell types. Neurosecretory cells were evolved to transmit the polarized signals from sensory cells/neurons to myocytes using chemical synapses. Finally, Westfall proposed that receptive, electrogenic and neurosecretory functions co-evolved in earlier protoneurons [Westfall, 1973; Westfall and Kinnamon, 1978].

In these earlier scenarios, the information about chemical (and even functional) heterogeneity of neuronal populations in cnidarians was very limited and 'neuron' was quite a generalized term linked primarily to its electrical properties such as conductor or pacemaker.

\section{Ancestral Secretory Cells as Evolutionary Precursors of Neurons}

With the introduction of transmitters as chemical messengers both within nervous systems and at the periphery, growing evidence suggested that even 'primitive' nervous systems in cnidarians could use similar intercellular messengers as signal molecules. Haldane proposed that neurotransmitters and hormones had their origin in unicellular organisms [Haldane, 1954]. A vital hypothesis was introduced by Grundfest who suggested that neurons arose from ancestral secretory cells [Grundfest, $1959,1965]$. The ancestral cell, according to this hypothesis, could be a sensory cell that developed the specialization of receptive surfaces and separate secretory poles. Then, 'the receptive and secretory portions of the cells gradually were displaced but remained connected by a region with conductile properties. The development of long processes terminating near blood vessels or on other cell types led to differentiation of neurosecretory cells.
Neurons were formed when the secretory activity became confined to the termination of the processes' [cited from Lentz, 1968]. Similar ideas were developed by Clark, again stressing the origin of neurosecretory cells from secretory epithelial cells [Clark, 1956a, b]. Therefore, these authors introduced the proposal that 'secretion is a primitive feature of the nervous system'.

Finally Sakharov, working on the problems of diversity of transmitter phenotypes (he used gastropod molluscs as major experimental models), proposed the idea of polygenesis of origins of neurons, where the diversity of transmitter phenotypes is a consequence of independent and parallel evolution of different neuronal lineages that preserve the ancestral type of transmitter specificity [Sakharov, 1970b, 1972, 1974b]. Sakharov also viewed transmitter specificity (equivalent to secretory specificity) as one of the most evolutionarily conserved characteristics of neurons. He was the first person to apply this and related criteria to identify individual homologous neurons in several gastropod lineages including characterization of homologous dopaminergic, serotonergic and peptidergic neurons in Lymnaea, Helix, Aplysia and Tritonia [Sakharov, 1970a, 1974a]. He also was one of the first modern neurobiologists to introduce the giant neurons of Tritonia [Veprintsev et al., 1964; Borovyagin and Sakharov, 1968] and Clione [Sakharov, 1960, 1965] to cellular and behavioral neuroscience.

To summarize that period, 'no consensus was reached, and the subject went out of style for much of the twentieth century' [Holland, 2003]. Moreover, the lack of reliable cytological markers at that time prevented speculation about possible heterogeneity of various neuronal elements and allowed only limited chances to trace the ancestry of cell lineages with reliable molecular reporters. At the same time, animal phylogeny was traditionally viewed as consisting of more or less gradual changes in the complexity of animal organization in different lineages [Brusca and Brusca, 2003]. Under this phylogenetic scheme, diffuse nerve-net like nervous systems were characteristic of the basal branches of the animal tree and parallel centralization events occurred several times within more derived lineages. In other words, this was a polyphyletic view concerning the origin of centralized brains in bilaterians, but this perception was dramatically changed with the advances in molecular biology and molecular phylogeny.

\section{Molecular Approaches to Study Neuronal Evolution}

The identification of genes and conserved molecular mechanisms involved in global animal body patterning 
[Carroll, 1995, 2008; De Robertis and Sasai ,1996] was the central conceptual milestone for evolutionary and developmental biology generally, and neuroscience in particular. First, it established that homeodomain transcription factors (otd/Otx - Pax 2/5/8 - Hox) are crucial in forming the anterior-posterior axes in bilaterians and in regional specification of the central nervous system following the anterioposterior gradient both in insects (Drosophila) and mammals [Hirth and Reichert, 2007].

The second surprise came with findings that dorsalventral patterning in both insects and vertebrates is controlled by evolutionarily conserved morphogens ( $\operatorname{sog}$ / Chordin and $d p p / B M P$ ) with mutually antagonistic actions [De Robertis and Sasai, 1996]. The site of action where sog/Chordin expression inhibits $d p p / B M P$ signaling corresponds to the region of the dorsal-ventral axis where the neuroectoderm is formed, from which eventually the nervous system is derived.

These findings revitalized the old hypothesis of Geoffroy Saint-Hilaire [1830] about the homology of ventral and dorsal sides of arthropods and vertebrates. In other words, it was widely accepted that during the evolution of chordates dorsoventral body axis inversion took place, and the ventral side of the ancestor of modern arthropods became the dorsal side for chordates [Arendt and NublerJung, 1994]. Furthermore, it appears that similar morphogens and transcription factors control the patterning and formation of the ventral central nervous system in insects and the dorsal nervous system in mammals, suggesting that these central nervous systems might be homologous and derived from a common ancestor of all bilaterian animals - the Urbilateria [reviewed by Hirth and Reichert, 2007].

By comparison of expression patterns of these genes across various bilaterians (e.g. mouse, ascidian and Drosophila), it was found that otd/Otx are expressed in the anterior part of the developing nervous system whereas Hox genes occur in the posterior regions, with the Pax2/5/8-expressing domain positioned between these regions [Hirth et al., 2003]. Such evolutionarily conserved patterning leads to the hypothesis of a tripartite brain in the last common ancestor for insects and chordates [Hirth et al., 2003]. In a definitive form it was considered as the hypothesis of monophyletic origin of the centralized brain. 'The available data suggest that only one ancestral, albeit rather complex, nervous system was at the origin of bilateral CNS evolution' [Hirth and Reichert, 2007].

In contrast, novel genome-wide data together with better phylogenomic reconstruction of evolutionary relationships among the animals seems to favor the alterna- tive scenario toward multiple origins of both complex brains and neurons. This theme will be further elaborated below.

\section{On the Independent Origin of Centralized Nervous Systems and Complex Brains}

The emerging picture of the Urbilateria ancestor as an organism with quite complex morphological and genomic organization is further supported by recently sequenced genomes of the sea anemone Nematostella (Anthozoa, Cnidaria) and Hydra (Hydrozoa, Cnidaria) as representatives of prebilaterian lineages [Meinhardt, 2002; MiljkovicLicina et al., 2004, 2007; Hwang et al., 2007; Kasbauer et al., 2007; Putnam et al., 2007; Simionato et al., 2007; Sullivan and Finnerty, 2007; Miller and Ball, 2008; Bosch et al., 2009]. Indeed, these genome projects revealed immense molecular and genomic complexity in cnidarians with remarkable preservation of many regulatory and nervous system-related genes homologous to those of vertebrates [Marlow et al., 2009]. As found in the analysis of genomic information from the sea slug Aplysia californica, however, some of these genes were lost in the faster-evolving lineages of insects and nematodes [Moroz et al., 2006].

In my opinion, however, the complexity of the ancestral genome does not truly support the hypotheses about the presence (or absence) of a complex centralized nervous system in the Urbilateria. The similarity of the overall body axes patterning, including patterning of the nervous system, does not imply that different neuronal lineages came from the same ancestral cell lineage (there is an enormous spectrum of innovations characteristic of parallel evolution with numerous convergent events); nor that neurons were clustered together in a hypothetical centralized nervous system of the common ancestor in a form of a primordial ventral cord.

The observed diversity of bilaterian nervous systems (especially from less investigated groups such as brachiopods, phoronids, echiurids, priapulids, hemichordates, echinoderms including crinoids, Xenoturbella, etc.) and recent reconstructions of the animal phylogeny [Holland, 2003; Bourlat et al., 2006; Dunn et al., 2008] can challenge this view of a monophyletic origin of bilaterian CNS from an ancestral centralized nervous system in the Urbilateria.

\section{Phylogenetic Analysis}

Figure 1 illustrates the phylogenetic relationship among representative animal phyla and the presence or absence 


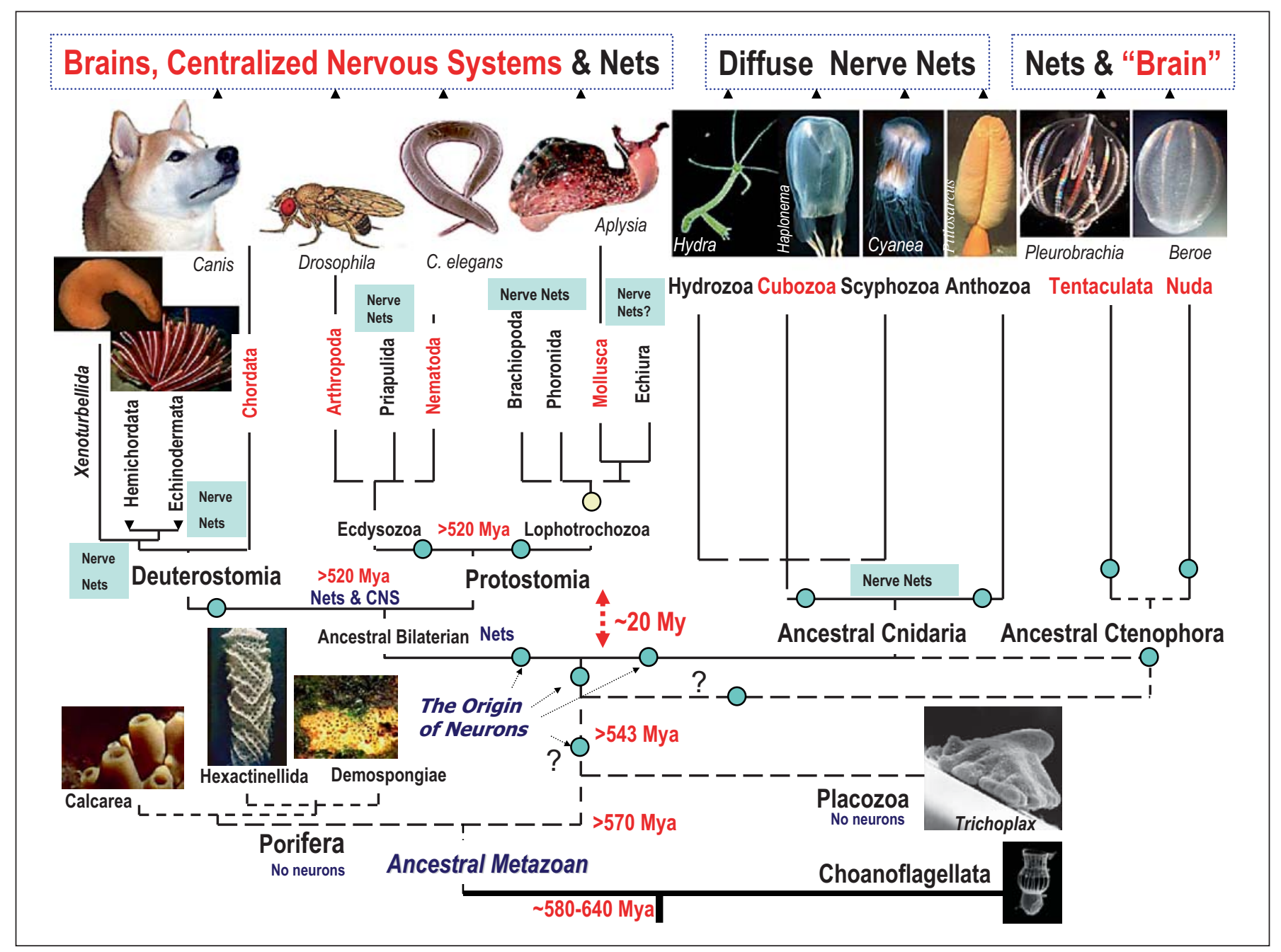

Fig. 1. Parallel evolution and diversity of nervous systems. The current view of evolutionary relationships in the animal kingdom is combined with the presence or absence of a central nervous system (CNS) or brain. One of the definitions of the CNS is the concentration of neuronal cells within a defined organ-type structure where neurons and neuronal processes can be supported (surrounded) by other cell types (e.g. glia or connective tissues) to maintain a controllable microenvironment for neuronal functioning. Choanoflagelates (eukaryotic algae-like organisms) are placed at the base of the tree as a sister group for Metazoa. Two basal metazoan phyla (Porifera and Placozoa) do not have recognized neurons. Two other prebilaterian/basal metazoan phyla (Cnidaria and Ctenophora) have well-defined neurons and nerves (however, only ctenophores have 'true' muscles of mesodermal origin). Although neuronal organization in basal Metazoa is superficially presented as a nerve net, many species have a prominent concentration of neuronal elements, and numerous and apparently autonomous networks governing surprisingly complex and well coordinated behaviors [Mackie 1990]. Cubozoa have well developed eyes and a ganglionic organization associated with rhopalia which can be described in terms of a centralized nervous system. Similarly, there is a well-defined concentration of neural elements associated with locomotory combs in Ctenophora. Chordates, nem- atodes, molluscs and arthropods have well-defined central nervous systems, while in other bilaterians shown in the diagram the gross anatomical organization of their nervous systems can be similar or even simpler than those in selected cnidarians and ctenophores. Centralization of nervous systems occurred in parallel within several lineages representing all three major domains in bilaterians (Deuterostomes, Ecdysozoa and Lophotrochozoa). Only representative groups of the 36 known animal phyla are shown in the diagram. Circles indicate possible events of multiple origins of neurons. See text for details. This reconstruction of phylogenetic relationships among phyla is a combined view based upon recent large-scale molecular/phylogenomic analyses of several dozen proteins from representatives of more than 15 animal phyla [Halanych, 2004; Valentine, 2004; Bourlat et al., 2006; Dunn et al., 2008; Philippe et al., 2009; Mikhailov et al., 2009]. The origin of animals can be traced back to about 600 million years ago (Mya). However, the extant animal phyla might have more recent evolutionary history. It appears that the origin of major bilaterian groups occurred within a relatively short geological time (probably within 20 million years or even less). As a result, the accurate evolutionary relationships among basal lineages and major bilaterian phyla are not well resolved (dotted lines). Possible timing of the divergence in the diagram is indicated as Mya. 
of centralized nervous systems across animal phyla. In all three established superclades of bilaterian animals (Deuterostomes, Ecdysozoa and Lophotrochozoa) there are phyla with well-defined compact brains/cords and phyla with non-centralized, diffuse nervous systems that superficially can be termed 'nerve net(s)'. Obviously, two possible evolutionary scenarios can be considered.

In the monophyletic hypothesis, the Urbilateria had a complex ancestral CNS which was lost multiple times in different bilaterian lineages (e.g. brachiopods, phoronids, echiurids, priapulids, hemichordates, echinoderms). Although simplification and reduction of selected regions of a nervous system could be explained as the result of sensory deprivation or a parasitic life style, it is difficult to explain numerous examples of an apparent dissociation of a compact nervous system into different cords or even its complete disintegration to a diffuse nerve net in free living, sometimes quite mobile (predatory) organisms. It assumes a loss of evolutionarily conserved mechanisms involved in establishing body axes and patterning that affect more than just the nervous system. In fact, at the time of this writing, there are no examples where decentralization or loss of a centralized brain is described for evolution of a lineage with free living (not parasitic) descendants. Even in ascidians, a reduced and simplified central brain (a result of a sessile life-style in adults) still can be recognized as a single central ganglion. Even though loss of the centralized neuronal structure can not be excluded in principle [e.g. the loss of a larval 'brain,' or apical organ, during metamorphosis; Nielsen, 2005], the monophyletic scenario starting from a centralized ancestral nervous system in the Urbilateria followed by catastrophic reduction, decentralization and losses in multiple bilaterian groups (e.g. phoronids, brachiopods) seems highly unlikely.

In contrast, the polyphyletic hypothesis puts forward the scenario that the centralized nervous systems and complex brains evolved more than once in different bilaterian lineages. Thus, the Urbilateria might have an uncentralized, possibly nerve net-like organization without the prerequisite well-defined location at the dorsal or ventral surfaces (although some concentration of neuronal elements could be present in locomotory, feeding and sensory regions).

The current animal phylogeny (fig. 1) implies that the centralization of nervous systems occurred at least 5-7 times in evolution (possibly even more often). For example, it might have happened independently in the lineages leading to: (i) chordates, (ii) arthropods, (iii) nematodes, (iv) annelids, and (v) molluscs.
In this respect, representatives of the systematically most diverse animal group - Mollusca - include a number of interesting and documented cases where at least 3-4 independent events of the centralization of nervous systems might have occurred in parallel within different lineages of the same phylum. Indeed, the prototypic nervous system of molluscs is called tetraneury with ventral, lateral and anterior loops and cords. It appears to have a dual origin (as in many other protostomes); two parts might be derived from the episphere lateral to the apical organ and other components are derivatives of elements from the circumplastoporal nerve ring around the blastopore [see Nielsen, 2005 for details] and possibly body walls [Jacob, 1984]. In the basal molluscan lineages (e.g. aplacophora, monoplacophora and chitons) it is possible to see the preservation of this ancestral tetraneury stage without well-defined ganglia or a centralized brain (fig. 2) [chapters 22-25 in Bullock and Horridge, 1965]. In the cephalopods, however, this organization is converted into the complex and highly compact brains (with about half a billion neurons) currently observed in Octopus or Sepia (fig. 2). The nervous system of Nautilus is a perfect example of an 'intermediate' level of centralization in the cephalopod lineage. The Nautilus CNS is described as a concentration of neurons in major cords that are morphologically similar to the swelling of large nerves with multiple neurons located in these cords [Young, 1965].

In gastropod molluscs, the basal groups such as limpets (Acmaea and Lottia) have nervous systems that also resemble those in monoplacophora [see chapter 22 in Bullock and Horridge, 1965; Brusca and Brusca, 2003]. Yet again, in three lineages of prosobranchs, opisthobranchs and pulmonate molluscs (fig. 2) it is possible to observe different degrees of centralization of individual ganglia [see details in chapter 23 of Bullock and Horridge, 1965]. The nudibranch molluscs (e.g., Tritonia, Coryfella or Melibe) have all ganglia (except the buccal) fused into the single mass forming a compact brain but with lobes and regions that are homologous to individual ganglia of gastropod molluscs. Thus, it is possible to reconstruct the organization of nervous systems in gastropod and cephalopod ancestors as primarily tetraneury with ventral, lateral and anterior loops and cords.

\section{The Diversity of Bilaterian Nervous Systems}

It also should be noted that the entire diversity of nervous systems across bilaterians can not be viewed as a simplified ventral versus dorsal nerve cord-like organization, and that the bilaterian CNS can be generated from different cell sources with different developmental and 


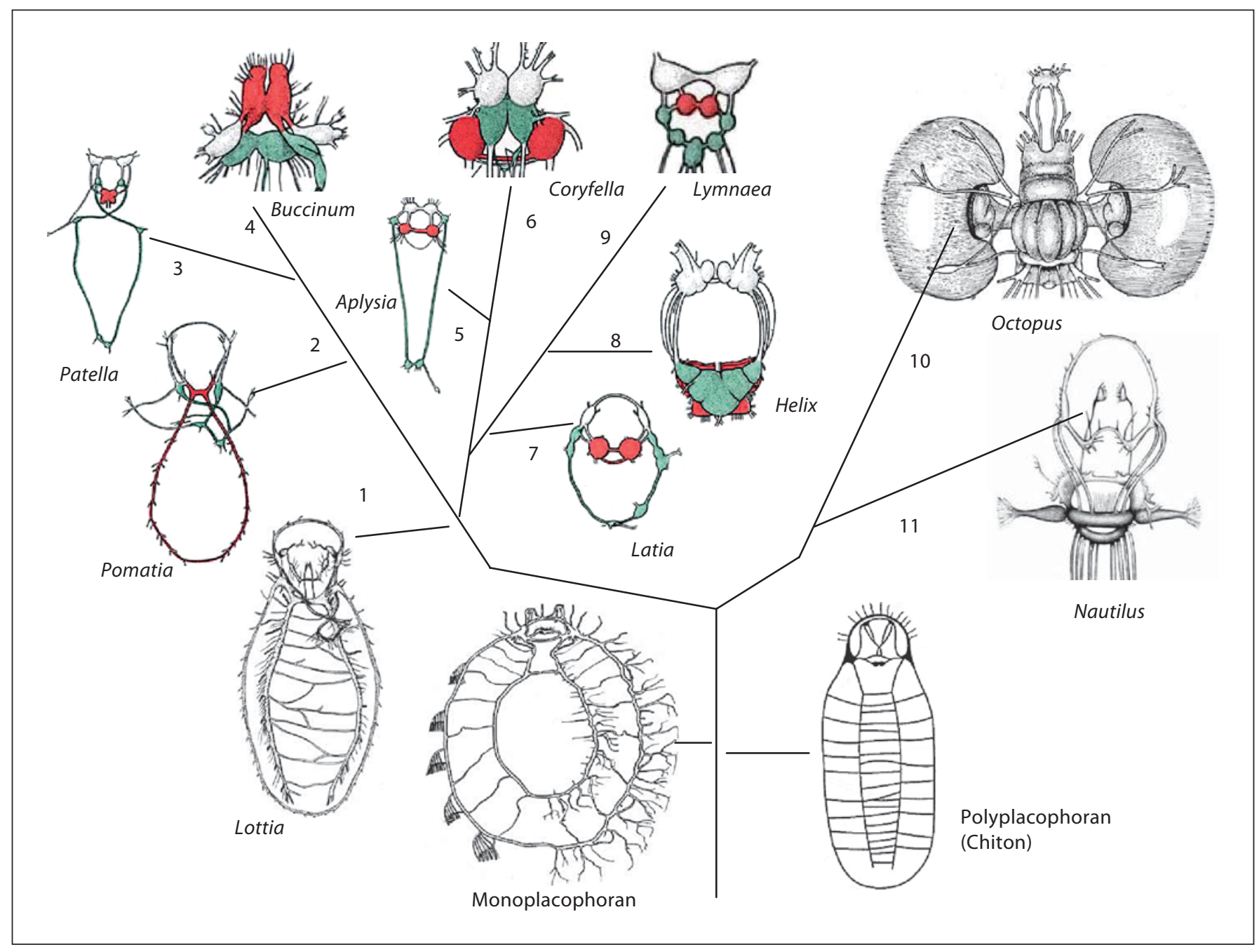

Fig. 2. Multiple occurrences of nervous system centralization in representatives of the phylum Mollusca. This diagram shows illustrative examples of nervous system centralization in two molluscan classes: Gastropoda (\#1-9) and Cephalopoda (\#10-11). The schematic outline of the anatomy of nervous systems in representatives of several lineages is combined with phylogenetic relationships among these groups. Ancestral organization of the molluscan nervous system (=tetraneury) is preserved in the two basal taxa Monoplacophora and Polyplacophora (or Chitons). Their nervous systems consist of two major elements: pedal and lateral or pleuro-parietal cords forming a visceral loop as well as cerebral and buccal loops located in the anterior part of animals. This pat- tern can also be recognized in Archogastropoda, represented here by the limpet Lottia (\#1) and Pomatia (\#2). Centralization of nervous systems occurs independently in various groups of prosobranch (\#2-4), opisthobranch (\#5-6), pulmonate (\#7-9) and cephalopod (\#10-11) molluscs. The derivatives of the pedal cords (the pedal ganglia) are shown in red; the components of the visceral loop (derivatives of pleural-parietral cords) are shown in green; and the cerebral ganglia are uncolored. Color coding has not been applied to cephalopod molluscs due to the more complex $3 \mathrm{D}$ organization of their brain. The modified diagrams of different molluscan nervous systems are from Bullock and Horridge [1965], fig. 22.6a, 23.3, 23.8a, 25.2, 25.5a). See text for details. evolutionary histories. A possible dual nature of bilaterian brain development was proposed by Claus Nielsen [Nielsen, 2005] with the possibility of a distinctly different organization of nervous systems in brachiopods, phoronids, echinoderms, etc. In addition, the evolutionary fate of a larval 'brain' is unclear - although the larval apical organ is the universal characteristic of the majority of phyla including cnidarians and ctenophores (with the exception of arthropods, nematods and chordates). 
At least five distinct morphological types of nervous organization can be recognized in bilaterians (yet without well established homologous regions and cell lineages across phyla):

(i) the dorsal 'hollow tube' characteristic of chordates;

(ii) a ventral cord characteristic of arthropods, annelids, sipunculids and many other groups - although exact homologies and molecular markers for various regions of the ventral cords have not been established across phyla;

(iii) the tetraneury in molluscs (fig. 2) - nervous organization that is not clearly related to the ventral cord and still largely uninvestigated using the tools of molecular biology;

(iv) basiepidermal nerve net-like nervous systems in hemichordates, Xenoturbella, Acoela, etc;

(v) enigmatic nervous systems found in echinoderms - these nervous systems are difficult to relate to any extant nervous systems in other phyla.

Enigmatic echinoderm nervous systems are diffuselike with apparent concentrations of neuronal elements in radial arms or body surfaces reflecting the pentameric symmetry of the group. Neuronal elements in echinoderms, however, can not easily be derived from the traditional ectodermal nervous system. Historically, up to four distinct nervous systems can be recognized in Crinoids [Harrison and Chia, 1997]. One of the recognized echinoderm nervous systems (ectoneural) is suggested to be derived from the ectoderm, two neural systems (hyponeural and apical) can be derived from mesoderm/coelomic epithelium, and one (entoneural) appears to be of endodermal origin. Clearly, the ongoing genomic efforts (e.g. the sequenced genome from the sea urchin and transcriptome projects on other echinoderm species) together with mapping of different neuronal lineages across echinoderm species will help to establish homologies and characterize their relationships with neuronal structures in other phyla.

In fact, even establishing homologies in the longitudinal nerve cords across bilaterians is uncertain [Minelli, 2009]. For example, it is assumed that the anterior brain and longitudinal nerve cord evolved independently in the case of annelids [Golding, 1992; Dorresteijn et al., 1993] and the majority of molluscs [Cephalopoda, Gastropoda, Bivalvia and Scaphopoda; Haszprunar, 2000; Raineri, 2000]. As indicated above, the enormous diversity within these lineages presents a unique opportunity to study mechanisms of the evolution of nervous systems and the origins of novelties in neuronal organization and function. Interestingly, the dual origin of the central nervous system is not limited to lophotrochozoan groups, it is also suggested for the onychophorans [Eriksson et al., 2003] .

The hypothesis of independent origin of complex brains does not contradict observed data related to the widespread modular type molecular mechanisms [Davidson et al., 2002; Prud'homme et al., 2006; Gompel and Prud'homme, 2009] controlling the overall patterning of nervous systems, development or animal body axes. The modular organization of many gene-regulatory pathways and combinatorial logics of the operation of multiple transcription factors provides endless opportunity for determination of complex cellular phenotypes.

Recent data from hemichordates clearly illustrate the preservation of overall patterning of expression of evolutionarily conserved homeodomain-related transcription factors and morphogens along the main body axes without the centralized nervous system [Lowe et al., 2003, 2006; Lowe, 2008]. Moreover, genes involved in regionalization of nervous systems in chordates and insects are not expressed in hemichordate neurons but are widely expressed in distinct non-neuronal cell populations. It is difficult to conclude that hemichordates are examples of secondary reduction, simplification or loss of centralized nervous systems [however, see Nomaksteinsky et al., 2009]. Hemichordates are one of the ancient lineages tracing their origin to one of the earliest known Cambrian fossil formations. More likely, hemichordates represent a basal/ancestral state of neuronal organization with a diffuse net-like nervous system [Holland, 2003] located in the epithelium. A similar diffuse nervous system was found in a newly established deuterostome phylum Xenoturbellida [recognized as a sister taxon to hemichordates/echinoderms; Bourlat et al., 2006]. Thus, out of four known deuterostome phyla, only chordates possess a centralized nervous system. This further supports the ancestral placement of basiepidermal diffuse nerve-net organization in the common ancestor of all deuterostomes.

Molecular data from Acoela as a basal bilaterian lineage [however, see Egger et al., 2009] also support a simple planula-like urbilaterian and apparently independent origin of many bilaterian features [Hejnol and Martindale, 2008a, b] including an ancestral uncentralized nervous system in the Urbilateria.

\section{Emerging Molecular Markers for Specification of \\ Neuronal Lineages across Phyla}

In addition to already described transcription factors and morphogens, other components and combinations of genes are also involved in the specification of neuronal 
phenotypes including those controlling establishing distinct transmitter phenotypes [Flames and Hobert, 2009]. This calls for careful chemical neuroanatomical/neurogenomic mapping of different neuronal lineages across phyla and the use of novel neuron-specific markers to find homologous neurons and identify cell lineages involved in the generation of diverse populations forming different types of nervous systems.

Comparative neurogenomics and precise molecular anatomy/taxonomy of the nervous organization is in its early stages [Nelson et al., 2006a, b; Sugino et al., 2006], and there are enormous gaps in our knowledge about chemical/molecular neuroanatomy in the majority of bilaterian phyla. Nevertheless, some pioneering work in this direction illustrates that it is possible to identify homologous cell-/neuron-type specific lineages across phyla [Tessmar-Raible et al., 2007]. It appears that cell-lineage specification with molecular fingerprint tools to reconstruct cell lineage phylogeny [see review by Arendt, 2005,2008 ] will provide a powerful approach to test the polygenetic origin of complex brains and neurons through dynamic interactions and combination of ancestral cellular lineages.

\section{On the Independent Origin of Neurons}

In the broad sense, discussion about multiple origins of neurons should start with the identification of universal criteria and/or molecular markers that would recognize neurons across phyla in an unbiased manner. Unfortunately, comparative data dealing with the genomic bases of neuronal identity and diversity are very limited today; however, six key points supporting the hypothesis of a polygenetic origin for neurons can be briefly outlined as follows (a more detailed discussion will be reported as a separate manuscript).

First, it is important to note that pan-neuronal genes and 'universal' neuronal 'master genes', or markers that apply equally to all neurons (but not other cell types), are currently unknown for all phyla, especially for basal metazoans (including ctenophores). If they do not exist, this situation would be compatible with the scenario of multiple origins of neurons during the evolution of metazoans.

Second, recent data suggest that neural specification in the basal anthozoan Nematostella vectensis appears to occur through a mechanism independent from that of the classical cnidarian model - the hydrozoan Hydra [Marlow et al., 2009]. Specifically, neurons apparently

On the Independent Origins of Complex

Brains and Neurons originate during development in both the ectoderm and the endoderm and their molecular markers and potentially stem-type cells are different from those found in Hydra. Again, if neurogenesis in both species and events within different cell lineages of the same species occur from different precursors and/or by different molecule mechanisms - this would favor the idea of independent origins of neurons.

Third, in many protostomes (including molluscs) neurons later forming a centralized nervous system can derive from different and apparently unrelated regions during development [Nielsen, 2005]. For example, neurons in molluscs can originate from regions around the apical organ, around ciliary bands, from regions within the body wall, etc. Apparently, different neuronal lineages can be labeled by different molecular markers and, therefore, they might not be genealogically related.

Fourth, genes involved in nervous system patterning might not be exclusively expressed in neurons [Hinman et al., 2003; Lowe et al., 2003]. For example, expression of Hox and other body patterning genes are widely distributed in the surface epithelial layers but without recognizable neuronal localization in hemichordates [Lowe et al., 2003] or ctenophores [Pang and Martindale, 2008]. In contrast, in ctenophores selected homeodomain-containing genes are expressed in neuronal structures but these genes (e.g. PRD class genes) apparently are not expressed in neurons of bilaterian animals [Pang and Martindale, 2008].

Fifth, it appears that not all neurons originate in the epidermis. In cnidarians, neurons also arise in the endoderm [Westfall and Elliott, 2002]; and in echinoderms different nerve nets apparently have coelomic/mesodermal and endodermal origin [see above and Harrison and Chia, 1997]. It is interesting that in cnidarians expression of Hox genes was detected in the endoderm [Finnerty et al., 2004; see also a discussion related to trans-differentiation, mesodermal and muscle specific genes and markers in cnidaria; Seipel et al., 2004; Galle et al., 2005; Seipel and Schmid, 2005, 2006; Reber-Muller et al., 2006], whereas the expression of 'anterior' Hox genes has been found in the mesoderm of the juvenile rudiment of the sea urchin [Arenas-Mena et al., 1998, 2000].

Sixth and finally, there is the possibility of independent origin of various sensory structures such as statocysts and olfactory receptors across phyla, whose ancestry can be traced to various classes of ciliated cells. Reconstruction of the evolution of photoreceptors is better investigated; apparently this class of sensory cells is associated with a defined cell lineage(s) across phyla [Ar- 
endt, 2008], but independent recruitment of multiple gene regulatory networks to establish complex sensory structures such as chambered eyes in molluscs (particularly in cephalopods) is suggested by various investigators [Ogura et al., 2004; Fernald, 2006].

In summary, it is a plausible scenario that neuron-like characteristics in different cell lineages evolved independently to control local integrative functions as polarized secretory cells. Such integration could be potentially achieved without specialized synaptic connections, using a volume-type of signaling and different classes of secretory products (e.g. signal peptides and low molecular weight transmitters). Later, neuron-like cells from different tissue sources or even embryonic layers could establish novel connections with other cells including other local neurons to speed up signaling and facilitate coordination of multiple sensory signals and effectors within one functionally unified but morphologically more diffuse nervous system.

\section{What Is a Neuron?}

It is quite easy to recognize a neuron in vertebrates or arthropods; however, even the identification of neurons as a defined cell population in basal metazoans or during development in many bilaterian lineages is less straightforward. Obviously, establishing universal criteria to be applied is essential in an analysis of the origin and evolution of nervous systems. Are there any such universal criteria? Is there a universal molecular tool-kit that defines a neuron? What is a neuron from the genomic standpoint? Neither action potentials nor specialized synapses are absolute prerequisites of neurons. Historically, there can be many transition forms within the same cell lineage from a simple secretory cell without defined processes to a highly polarized neuron with hundreds of specialized processes and synapses. In generalized terms, the following definitions can be considered, but they need to be carefully validated in a broad comparative survey which includes the basal Metazoa:

(i) Neurons are asymmetrical, highly polarized secretory cells with multiple cellular compartments that are specialized for directed information processing to other cell types, and which demonstrate experience-dependent plasticity and elaborated integrative functions. In my opinion, the presence of short- and long-term plasticity features is an essential component of a neuron and, perhaps, many proneuronal cells as well. (ii) Neurons can make polarized and specialized connections (synapses) but do not necessarily do so in all animals and nervous circuits, as documented in basal metazoans and various bilaterians. Hormonal-like, volume transmission can serve many true integrative and neuronal functions without a specialized synapse and synaptic cleft if targets are localized within a few micrometers from the transmitter release points, or if fast chemical transmission is not required (e.g. for many sessile animals with limited motor reactions or for vegetative processes).

(iii) To support its integrative functions, a neuron expresses more genes and gene products than other cell types. This becomes an easily testable hypothesis when one can directly determine all genes expressed in a given neuron using next generation sequencing technologies [see Moroz et al., 2007; Kohn et al., 2008; Moroz, 2009]. Our data using single identified Aplysia and Cancer neurons suggest that a large fraction of an animal's genome is expressed by a single neuron.

Given these proposed generalized features of neurons, it is reasonable to address the question: what is the molecular/genomic foundation that lets a cell be or not be a neuron? I propose that a complex and coordinated transcriptome response in a cell with co-expression of multiple genes (or even a majority of genes) at any given time is the major requirement to be a neuron in the first place. It might also be the major component in development of the logic of gene regulation that drives neural evolution and the origin of various cell types in nervous systems. This leads to the question of what factors could initiate such a generalized, integrative and adaptive transcriptome response in earlier cells and promote the appearance of neuronal-like properties?

\section{Adaptive Injury/Regeneration Responses in Early Animals as Generalized Neurogenic Factors in Evolution}

The proposed hypothesis can be summarized as one of the possible scenarios of the origin of integrative neuroid elements and first transmitters.

In the earliest stages of neuronal evolution, massive gene expression could be achieved (and triggered) as a result of a stress/injury response. Thus, injury might be the major neurogenic factor in evolution. Indeed, damaging and high threshold nociceptive stimuli that are not sufficient to kill a cell can induce an integrated repair process, distant chemical signaling, and re-growth of 
asymmetric proneuronal processes, thereby acting as inductors of a novel neuronal-like phenotype in the first place. Thus, neurons might have evolved in ancestral metazoans as a result of development in the adaptive cellular regenerative response to localized injury and stress, leading to a coordinated (potentially defensive) reaction and behavior of the entire organism.

Furthermore, an injury by its nature might lead to the release of an array of chemical messengers that can act as primordial signal molecules or transmitters. For example, such widespread cellular metabolites as ATP, NO, protons and Glu might have acted as the first, initially non-specific, transmitters involved in the fast signaling associated with injury. These are metabolically cheap and abundant chemical intermediates that were co-opted to induce rapid localized repair and defensive responses.

At the same time, different cells might also use peptide signal molecules for slower, more specific and coordinated morphogenic and behavioral responses - which therefore act similarly to extant neuropeptides. Several factors might contribute to this process. Neuropeptides are easy to synthesize in any cell; small (oligo) peptides have a wide range of conformations and, therefore, can be recruited to activate a number of receptors and potential targets. (Neuro)peptide-type molecules can be evolved independently and various protoneuronal cells might develop this type of signaling in parallel. Signal peptides are widely used in virtually all eukaryotic organisms including unicellular eukaryotes and it is entirely possible that the first nervous systems were highly peptidergic. In fact, neuropeptides are omnipresent as co-transmitters in a majority of extant neurons within the well-studied nervous systems of vertebrates, mollusc, arthropods, flat worms, and cnidarians; indeed, this characteristic might be a fundamental property of virtually every nervous system. These first 'true' peptide transmitters could also act as growth factors controlling trans-differentiation. These chemical signals/growth factors were originally 'preadapted' to the repair, regeneration and re-establishment of integrative systems for intercellular directional communications.

As a result, there could be a cascade of (possibly autocatalytic) processes supporting and maintaining the simultaneous expression of multiple genes and eventually a massive polarized relocalization of gene products [RNAs or proteins - see Martin and Ephrussi, 2009] to different cell compartments - the universal process (used today as part of synaptic and plasticity mechanisms) supporting directional signaling, regeneration and interactions with multiple targets.

On the Independent Origins of Complex Brains and Neurons
In summary, it is very likely that early secretory/peptidergic cells were evolutionary precursors of neurons and that the massive gene upregulation needed to repair an injury was co-opted to serve the needed neuronal integrative functions. It is also possible that signaling peptides were the first (neuro)transmitters and that classical transmitters (e.g., serotonin, dopamine, or acetylcholine) were co-opted later in evolution. One of the predictions of this hypothesis is that similar evolutionarily conserved molecular processes defining phenotypes of secretory/ 'pro-neuronal' cells can be found in basal metazoans without recognizable nervous systems including placozoans or mesozoans, and in representatives of different classes of vertebrates [Vigh et al., 2004] and sponges [Richards et al., 2008] as well as in early embryogenesis of extant bilaterians, cnidarians and ctenophores.

\section{Conclusions and Perspectives in Evolutionary Neuroscience}

Although our understanding of early events underlying neuronal evolution and the molecular diversity of nervous systems is still in its initial stages, this paper emphasizes the extensive degree of parallel evolution that has recently become apparent and outlines scenarios of independent origins for neurons and centralized nervous systems. Only a few representatives from about 35 animal phyla have currently been investigated from such comparative and evolutionary perspectives, with molluscans and basal metazoans as emerging models in this direction. Nevertheless, recent molecular data and novel animal phylogeny imply that both complex brains and neurons evolved at least 5-7 times during the course of animal evolution. Starting from the Precambrian time (more than 550-600 million years ago), rapid diversification of different types of neuronal organizations was paralleled by the formation of various bodyplans within the extant animal phyla.

Modular gene regulatory, and various transcriptional networks, as well as master regulatory elements in the animal genomes might have been recruited and co-opted multiple times in the course of evolution leading to the appearance of numerous neuronal lineages and complex neuronal phenotypes integrated as part of sensory organs and brains. The recent efforts of regenerative medicine (with the goal of manipulating specification of neuronal cell lineages from stem cells using a combination of transcription factors and master genes) might in some ways benefit from understanding such ancestral modular or-

Brain Behav Evol 2009;74:177-190 
ganization and logic of gene regulation in control of neuronal identity and diversity.

Neurosystematics, which is the unbiased classification of neurons in neural circuits across species, is a novel direction in fundamental and comparative neuroscience it is inherently linked to our understanding of the evolution and principles of organization within neural circuits. The ideal system of classification of neurons (or the 'natural' system of neurons) should blend the emerging genomics data related to neuronal specificity and diversity with the power of evolutionary approaches. It should include an integration of phylogenic relations among the animals with the identification and reconstruction of ancestral cellular lineages within nervous systems, as well as establish neuronal homologies or neuronal innovations across phyla (e.g. as the result of convergent evolution following the functional specialization in circuits).

In a reconstruction of the dawn of neuronal organization, secretory cells can be considered as evolutionary predecessors of neurons. Consequently, peptides and a few low molecular weight metabolites (e.g. ATP, Glu, NO) [Moroz and Kohn, 2007] might be recruited as the evolutionarily earliest interneuronal messengers (or neuro-effector transmitters), whereas specialized synapses need not be absolute prerequisites for neurons. With some exceptions [e.g. Drosophila - Emes et al., 2008], however, invertebrate synapses can be as complex as those found in vertebrates, further indicating that parallel evolution of synaptic organization in diverse animal lineages is still poorly understood. Our initial genomic data suggest that molluscan synapses can be even more complex that those described in mammals [Kohn et al., 2008].

\section{Acknowledgements}

We are grateful to Mr. Jim Netherton for reading and discussing the text and two reviewers for helpful criticism and suggestions. LLM is supported by NIH and NSF grants 1RO1NS06076, R21RR025699, NSF-0744649, and in part by the McKnight Brain Research Foundation and UF Opportunity Funds.

\section{References}

Arenas-Mena C, Cameron AR, Davidson EH (2000) Spatial expression of Hox cluster genes in the ontogeny of a sea urchin. Development 127:4631-4643.

-Arenas-Mena C, Martinez P, Cameron RA, Davidson EH (1998) Expression of the Hox gene complex in the indirect development of a sea urchin. Proc Natl Acad Sci USA 95:1306213067.

-Arendt D (2005) Genes and homology in nervous system evolution: comparing gene functions, expression patterns, and cell type molecular fingerprints. Theor Biosci 124: $185-197$.

-Arendt D (2008) The evolution of cell types in animals: emerging principles from molecular studies. Nat Rev Genet 9:868-882.

-Arendt D, Nubler-Jung K (1994) Inversion of dorsoventral axis? Nature 371:26.

Borovyagin VN, Sakharov DA (1968) Ultrastructural organization of giant neurons in Tritonia (Atlas). Moscow: Nauka (in Russian).

Bosch TC, Augustin R, Anton-Erxleben F, Fraune S, Hemmrich G, Zill H, Rosenstiel P, Jacobs G, Schreiber S, Leippe M, Stanisak M, Grotzinger J, Jung S, Podschun R, Bartels J, Harder J, Schroder JM (2009) Uncovering the evolutionary history of innate immunity: the simple metazoan Hydra uses epithelial cells for host defence. Dev Comp Immunol 33:559-569.
Bourlat SJ, Juliusdottir T, Lowe CJ, Freeman R, Aronowicz J, Kirschner M, Lander ES, Thorndyke M, Nakano H, Kohn AB, Heyland A, Moroz LL, Copley RR, Telford MJ (2006) Deuterostome phylogeny reveals monophyletic chordates and the new phylum Xenoturbellida. Nature 444:85-88.

Brusca RC, Brusca GJ (2003) Invertebrates, 2nd ed. Sunderland, MA: Sinauer Associates, Inc.

Bullock TH, Horridge GA (1965) Structure and function in the nervous systems of invertebrates. San Francisco, CA: Freeman.

Carroll SB (1995) Homeotic genes and the evolution of arthropods and chordates. Nature 376:479-485

Carroll SB (2008) Evo-devo and an expanding evolutionary synthesis: a genetic theory of morphological evolution. Cell 134:25-36.

Chun C (1880) Die Ctenophoren des Golfes von Neapel. Fauna Flora Neapel, Monogr:1-313.

Clark RB (1956a) On the origin of neurosecretory cells. Ann Sci Nat Zool 18:199-207.

Clark RB (1956b) On the transformation of neurosecretory cells into ordinary nerve cells. Fysiogr Sallsk Lund, Forth 26:82-89.

Claus C (1878) Studien uber Polypen und Quallen der Ardia. Denkschr Acad Wiss Wien:164.
Davidson EH, Rast JP, Oliveri P, Ransick A, Calestani C, Yuh CH, Minokawa T, Amore G, Hinman V, Arenas-Mena C, Otim O, Brown CT, Livi CB, Lee PY, Revilla R, Rust AG, Pan Z, Schilstra MJ, Clarke PJ, Arnone MI, Rowen L, Cameron RA, McClay DR, Hood L, Bolouri H (2002) A genomic regulatory network for development. Science 295:16691678.

De Robertis EM, Sasai Y (1996) A common plan for dorsoventral patterning in Bilateria. Nature 380:37-40.

Dorresteijn AWC, O'Grady B, Fischer A, Porchet-Hennere E, Boilly-Marer Y (1993) Molecular specification of cell lines in the embryo of Platyneris (Annelida). Roux's Archiv Dev Biol 202:260-269.

Dunn CW, Hejnol A, Matus DQ, Pang K, Browne WE, Smith SA, Seaver E, Rouse GW, Obst M, Edgecombe GD, Sorensen MV, Haddock SH, Schmidt-Rhaesa A, Okusu A, Kristensen RM, Wheeler WC, Martindale MQ, Giribet G (2008) Broad phylogenomic sampling improves resolution of the animal tree of life. Nature 452:745-749.

-Egger B, Steinke D, Tarui H, De Mulder K, Arendt D, Borgonie G, Funayama N, Gschwentner R, Hartenstein V, Hobmayer B, Hooge M, Hrouda M, Ishida S, Kobayashi C, Kuales G, Nishimura O, Pfister D, Rieger R, Salvenmoser W, Smith J, Technau U, Tyler S, Agata K, Salzburger W, Ladurner P (2009) To be or not to be a flatworm: the acoel controversy. PLoS ONE 4:e5502. 
Emes RD, Pocklington AJ, Anderson CN, Bayes A, Collins MO, Vickers CA, Croning MD, Malik BR, Choudhary JS, Armstrong JD, Grant SG (2008) Evolutionary expansion and anatomical specialization of synapse proteome complexity. Nat Neurosci 11:799806.

Eriksson BJ, Tait NN, Budd GE (2003) Head development in the onychophoran Euperipatoides kanangrensis with particular reference to the central nervous system. J Morphol 255:1-23.

- Fernald RD (2006) Casting a genetic light on the evolution of eyes. Science 313:1914-1918.

- Finnerty JR, Pang K, Burton P, Paulson D, Martindale MQ (2004) Origins of bilateral symmetry: Hox and dpp expression in a sea anemone. Science 304:1335-1337.

-Flames N, Hobert O (2009) Gene regulatory logic of dopamine neuron differentiation. Nature 458:885-889.

-Galle S, Yanze N, Seipel K (2005) The homeobox gene Msx in development and transdifferentiation of jellyfish striated muscle. Int J Dev Biol 49:961-967.

Geoffroy Saint-Hilaire, E (1830) Principes de philosophie zoologique. Paris: Pichon et Didier.

Golding DM (1992) Polychaeta: nervous system. In: Microscopic anatomy of invertebrates (Harrison FW, Gardiner SL, eds), vol 7, pp 155-179. New York: Wiley-Liss.

Gompel N, Prud'homme B (2009) The causes of repeated genetic evolution. Dev Biol: in press.

Grundfest H (1959) Evolution of conduction in the nervous system. In: Evolution of nervous control from primitive organisms to man (Bass AD, ed), pp 43-86. Washington DC: AAAS.

Grundfest H (1965) Evolution of electrophysiological properties among sensory receptor systems. In: Essays on physiological evolution (Pringle JWS, ed), pp 107-138. Oxford, UK: Pergamon Press.

-Halanych KM (2004) The new view of animal phylogeny. Annu Rev Eco Evol Syst 35:229256.

Haldane JBC (1954) La signalization animale. Anne Biol 58:89-98.

Harrison FW, Chia FS (eds) (1997) Echinodermata. New York: Wiley-Liss.

- Haszprunar G (2000) Is Aplacophora monophyletic? Cladistic point of view. Am Malacolog Bull 15:115-130.

- Hejnol A, Martindale MQ (2008a) Acoel development indicates the independent evolution of the bilaterian mouth and anus. Nature 456:382-386.

- Hejnol A, Martindale MQ (2008b) Acoel development supports a simple planula-like urbilaterian. Phil Trans R Soc Lond B Biol Sci 363:1493-1501.

Hertwig O, Hertwig R (1878) Das Nervensystem und die Sinnesorgane der Medusen (The nervous system and the sensory organs of the Medusa). Leipzig: Vogel.
Hinman VF, O’Brien EK, Richards GS, Degnan BM (2003) Expression of anterior Hox genes during larval development of the gastropod Haliotis asinina. Evol Dev 5:508-521.

-Hirth F, Kammermeier L, Frei E, Walldorf U, Noll M, Reichert H (2003) An urbilaterian origin of the tripartite brain: developmental genetic insights from Drosophila. Development 130:2365-2373.

Hirth F, Reichert H (2007) Basic nervous system types: One or many. In: Evolution of Nervous Systems (Kaas JH, ed), vol 1, pp 55-72. Amsterdam: Academic Press.

Holland ND (2003) Early central nervous system evolution: an era of skin brains? Nat Rev Neurosci 4:617-627.

Hwang JS, Ohyanagi H, Hayakawa S, Osato N, Nishimiya-Fujisawa C, Ikeo K, David CN, Fujisawa T, Gojobori T (2007) The evolutionary emergence of cell type-specific genes inferred from the gene expression analysis of Hydra. Proc Natl Acad Sci USA 104:1473514740 .

Jacob MH (1984) Neurogenesis in Aplysia californica resembles nervous system formation in vertebrates. J Neurosci 4:1225-1239.

- Kasbauer T, Towb P, Alexandrova O, David CN, Dall'armi E, Staudigl A, Stiening B, Bottger A (2007) The Notch signaling pathway in the cnidarian Hydra. Dev Biol 303:376-390.

Kleinenberg N (1872) Hydra - Eine anatomischentwicklungsgeschichtliche untersuchung (An anatomical-evolutionary investigation of $H y d r a)$. Leipzig: Wilhelm Engelmann.

Kohn AB, Jezzini S, Ha T, Bentley-Sloan J, M. C, Bobkova E, Lee C, Yu F, Shaw R, Li J, Colman B, Clouser C, Barbaciorus M, Shan A, Farmerie W, Moroz LL (2008) Nearly complete genomic profiling of individual identified neurons: SOLiD approach Soc Neurosci Meeting:880.881

Lentz TL (1968) Primitive nervous systems. New Haven, CT: Yale University Press.

Lichtneckert R, Reichert H (2007) Origin and evolution of the first nervous systems. In: Evolution of Nervous Systems (Kaas JH, ed), vol 1, pp 289-315. Amsterdam: Academic Press.

Lowe CJ (2008) Molecular genetic insights into deuterostome evolution from the direct-developing hemichordate Saccoglossus kowalevskii. Phil Trans R Soc Lond B Biol Sci 363: 1569-1578.

Lowe CJ, Terasaki M, Wu M, Freeman RM, Jr., Runft L, Kwan K, Haigo S, Aronowicz J, Lander E, Gruber C, Smith M, Kirschner M, Gerhart J (2006) Dorsoventral patterning in hemichordates: insights into early chordate evolution. PLoS Biol 4:e291.

Lowe CJ, Wu M, Salic A, Evans L, Lander E, Stange-Thomann N, Gruber CE, Gerhart J, Kirschner M (2003) Anteroposterior patterning in hemichordates and the origins of the chordate nervous system. Cell 113:853865 .
Mackie GO (1970) Neuroid conduction and the evolution of conducting tissues. Q Rev Biol 45:319-332.

Mackie GO (1990) The elementary nervous sytems revisited. Amer Zool 30:907-920.

- Marlow HQ, Srivastava M, Matus DQ, Rokhsar D, Martindale MQ (2009) Anatomy and development of the nervous system of Nematostella vectensis, an anthozoan cnidarian. Dev Neurobiol 69:235-254.

Martin KC, Ephrussi A (2009) mRNA localization: gene expression in the spatial dimension. Cell 136:719-730.

Meinhardt H (2002) The radial-symmetric hydra and the evolution of the bilateral body plan: an old body became a young brain. Bioessays 24:185-191.

Mikhailov KV, Konstantinova AV, Nikitin MA, Troshin PV, Rusin LY, Lyubetsky VA, Panchin YV, Mylnikov AP, Moroz LL, Kumar S, Aleoshin VV (2009) The origin of Metazoa: a transition from temporal to spatial cell differentiation. Bioessays 31:758-768.

Miljkovic-Licina M, Chera S, Ghila L, Galliot B (2007) Head regeneration in wild-type hydra requires de novo neurogenesis. Development 134:1191-1201.

Miljkovic-Licina M, Gauchat D, Galliot B (2004) Neuronal evolution: analysis of regulatory genes in a first-evolved nervous system, the hydra nervous system. Biosystems 76:75-87.

- Miller DJ, Ball EE (2008) Cryptic complexity captured: the Nematostella genome reveals its secrets. Trends Genet 24:1-4.

Minelli A (2009) Perspectives in animal phylogeny and evolution. Oxford, UK: Oxford University Press.

Moroz LL (2009) On the independent origins of neurons and complex brains: Insights from genomic and comparative analysis of basal animal lineages. Soc Neurosci Abst. 225.13/ B88. http://www.abstractsonline.com/plan/ start.aspx?mkey $=\{081 \mathrm{~F} 7976-\mathrm{E} 4 \mathrm{CD}-4 \mathrm{~F} 3 \mathrm{D}$ A0AF-E8387992A658\} http://www.abstractsonline.com/plan/AdvancedSearch.aspx

Moroz LL, Edwards JR, Puthanveettil SV, Kohn AB, Ha T, Heyland A, Knudsen B, Sahni A, Yu F, Liu L, Jezzini S, Lovell P, Iannucculli W, Chen M, Nguyen T, Sheng H, Shaw R, Kalachikov S, Panchin YV, Farmerie W, Russo JJ, Ju J, Kandel ER (2006) Neuronal transcriptome of Aplysia: neuronal compartments and circuitry. Cell 127:1453-1467.

Moroz LL, Jezzini S, Ha T, Yu F, Shaw R, Farmerie W, Panchin Y, Kohn A (2007) The genomic portrait of a characterized neuron: singlecell high-throughput expression profiling of identified neurons in Aplysia. Soc Neurosci Abst:208.223.

Moroz LL, Kohn AB (2007) On the comparative biology of NO synthetic pathways: parallel evolution of $\mathrm{NO}$ mediated signaling. In: $\mathrm{Ni}-$ tric oxide, advances in experimental biology (Trimmer B, Tota B, Wang T, eds), vol 1, pp 1-45. Amsterdam: Elsevier BV. 
Nelson SB, Hempel C, Sugino K (2006a) Probing the transcriptome of neuronal cell types. Curr Opin Neurobiol 16:571-576.

-Nelson SB, Sugino K, Hempel CM (2006b) The problem of neuronal cell types: a physiological genomics approach. Trends Neurosci 29: 339-345.

Nielsen C (2005) Larval and adult brains. Evol Dev 7:483-489.

- Nomaksteinsky M, Rottinger E, Dufour HD, Chettouh Z, Lowe CJ, Martindale MQ, Brunet JF (2009) Centralization of the deuterostome nervous system predates chordates. Curr Biol 19:1264-1269.

-Ogura A, Ikeo K, Gojobori T (2004) Comparative analysis of gene expression for convergent evolution of camera eye between octopus and human. Genome Res 14:1555-1561.

Pang K, Martindale MQ (2008) Developmental expression of homeobox genes in the ctenophore Mnemiopsis leidyi. Dev Genes Evol 218:307-319.

Pantin CFA (1956) The origin of the nervous system. Pubbl Staz Zool Napoli 28:171-181.

Parker GH (1919) The elementary nervous systems. Philadelphia, PA: Lippincott.

Passano LM (1963) Primitive Nervous Systems. Proc Natl Acad Sci USA 50:306-313.

- Philippe H, Derelle R, Lopez P, Pick K, Borchiellini C, Boury-Esnault N, Vacelet J, Renard E, Houliston E, Queinnec E, Da Silva C, Wincker P, Le Guyader H, Leys S, Jackson DJ, Schreiber F, Erpenbeck D, Morgenstern B, Worheide G, Manuel M (2009) Phylogenomics revives traditional views on deep animal relationships. Curr Biol 19:706-712.

- Prud'homme B, Gompel N, Rokas A, Kassner VA, Williams TM, Yeh SD, True JR, Carroll SB (2006) Repeated morphological evolution through cis-regulatory changes in a pleiotropic gene. Nature 440:1050-1053.

Putnam NH, Srivastava M, Hellsten U, Dirks B, Chapman J, Salamov A, Terry A, Shapiro H, Lindquist E, Kapitonov VV, Jurka J, Genikhovich G, Grigoriev IV, Lucas SM, Steele RE, Finnerty JR, Technau U, Martindale MQ, Rokhsar DS (2007) Sea anemone genome reveals ancestral eumetazoan gene repertoire and genomic organization. Science 317:86-94.
Raineri M (2000) Early neurogenesis pattern in Patella coerulea (Patellogastropoda) and its possible phylogenetic applications. Malacologia 42:131-148.

Reber-Muller S, Streitwolf-Engel R, Yanze N, Schmid V, Stierwald M, Erb M, Seipel K (2006) BMP2/4 and BMP5-8 in jellyfish development and transdifferentiation. Int Dev Biol 50:377-384.

Richards GS, Simionato E, Perron M, Adamska M, Vervoort M, Degnan BM (2008) Sponge genes provide new insight into the evolutionary origin of the neurogenic circuit. Curr Biol 18:1156-1161.

Sakharov DA (1960) On the automatism of the pedal ganglia in the pteropod molluscs Clione limacina. Proc Higher Ed (Biol Sci) 3: 60-62.

Sakharov DA (1965) Functional organization of giant neurons in molluscs. Adv Modern Biol 60:365-383.

- Sakharov DA (1970a) Cellular aspects of invertebrate neuropharmacology. Annu Rev Pharmacol 10:335-352.

- Sakharov DA (1970b) The foundations toward the system of neuronal cell (in Russian). Zhurnal Obschey Biologii (J Gen Biol - Russian) 31:449-457.

Sakharov DA (1972) Why are neurons different? (in Russian). Priroda 10:52-62.

-Sakharov DA (1974a) Evolutionary aspects of transmitter heterogeneity. J Neural Transm Suppl 11:43-59.

Sakharov DA (1974b) Genealogy of neurons. Moscow: Nauka.

-Seipel K, Schmid V (2005) Evolution of striated muscle: jellyfish and the origin of triploblasty. Dev Biol 282:14-26.

- Seipel K, Schmid V (2006) Mesodermal anatomies in cnidarian polyps and medusae. Int $J$ Dev Biol 50:589-599.

Seipel K, Yanze N, Schmid V (2004) Developmental and evolutionary aspects of the basic helix-loop-helix transcription factors Atonal-like 1 and Achaete-scute homolog 2 in the jellyfish. Dev Biol 269:331-345.
Simionato E, Ledent V, Richards G, ThomasChollier M, Kerner P, Coornaert D, Degnan BM, Vervoort M (2007) Origin and diversification of the basic helix-loop-helix gene family in metazoans: insights from comparative genomics. BMC Evol Biol 7:33.

- Sugino K, Hempel CM, Miller MN, Hattox AM Shapiro P, Wu C, Huang ZJ, Nelson SB (2006) Molecular taxonomy of major neuronal classes in the adult mouse forebrain. Nat Neurosci 9:99-107.

Sullivan JC, Finnerty JR (2007) A surprising abundance of human disease genes in a simple 'basal' animal, the starlet sea anemone (Nematostella vectensis). Genome 50:689692.

- Tessmar-Raible K, Raible F, Christodoulou F, Guy K, Rembold M, Hausen H, Arendt D (2007) Conserved sensory-neurosecretory cell types in annelid and fish forebrain: insights into hypothalamus evolution. Cell 129:1389-1400.

Valentine JW (2004) On the origin of phyla. Chicago, IL: The University of Chicago Press.

Veprintsev BN, Krasts IB, Sakharov DA (1964) Nerve cells in the nudibranch mollusc, Tritonia diomedia Bergh Biophys 9:327-335.

-Vigh B, Manzano e Silva MJ, Frank CL, Vincze C, Czirok SJ, Szabo A, Lukats A, Szel A (2004) The system of cerebrospinal fluid-contacting neurons. Its supposed role in the nonsynaptic signal transmission of the brain. Histol Histopathol 19:607-628.

-Westfall JA (1973) Ultrastructural evidence for a granule-containing sensory-motor-interneuron in Hydra littoralis. J Ultrastruct Res 42:268-282.

Westfall JA, Elliott CF (2002) Ultrastructure of the tentacle nerve plexus and putative neural pathways in sea anemones. Invert Biol 121: 202-211.

-Westfall JA, Kinnamon JC (1978) A second sensory-motor-interneuron with neurosecretory granules in Hydra. J Neurocytol 7:365379.

Young JZ (1965) The central nervous system of Nautilus. Phil Trans R Soc Lond B 249:1-25. 